\title{
Charles Perrault, Les Hommes illustres
}

\section{Benedetta Papasogli}

\section{Q OpenEdition}

\section{Journals}

\section{Edizione digitale}

URL: https://journals.openedition.org/studifrancesi/40628

DOI: 10.4000/studifrancesi.40628

ISSN: 2421-5856

\section{Editore}

Rosenberg \& Sellier

\section{Edizione cartacea}

Data di pubblicazione: 1 juillet 2004

Paginazione: 185

ISSN: 0039-2944

\section{Notizia bibliografica digitale}

Benedetta Papasogli, «Charles Perrault, Les Hommes illustres», Studi Francesi [Online], 142 (XLVIII | I) |

2004, online dal 30 novembre 2015, consultato il 09 septembre 2021. URL: http://

journals.openedition.org/studifrancesi/40628; DOI: https://doi.org/10.4000/studifrancesi.40628

Questo documento è stato generato automaticamente il 9 septembre 2021.

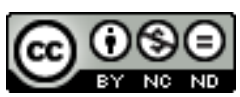

Studi Francesi è distribuita con Licenza Creative Commons Attribuzione - Non commerciale - Non opere derivate 4.0 Internazionale. 


\title{
Charles Perrault, Les Hommes illustres
}

\author{
Benedetta Papasogli
}

\section{NOTIZIA}

CHARLES PERRAULT, Les Hommes illustres. Avec leurs portraits au naturel. Texte établi, avec introduction, notes, relevé de variantes, bibliographie et index par D. J. CuLPIN, Tübingen, GunterNarr Verlag, 2003, «Biblio 17», pp. 535.

1 L'opera di cui D. J. Culpin presenta un'edizione moderna non fu tra quelle di Perrault che ebbero maggiore successo. Non ve ne sono state riedizioni integrali dal 1700, anno in cui uscì la seconda e definitiva versione dell'opera, con un secondo tomo che portava a cento il numero degli uomini illustri celebrati (in realtà, come vedremo, centodue: la cifra anomala invita a portare lo sguardo in un interessante retroscena del testo). A mezza strada fra il genere dell'elogio e la storiografia, intesa essa stessa come ricerca di esempi e lezione di saggezza, la raccolta non è totalmente di mano di Perrault; si nasconde dietro di essa la figura dell'erudito e collezionista Michel Bégon, che nel corso di una pur movimentata carriera di Intendente di qua e di là dall'oceano ebbe agio di mettere insieme una biblioteca di settemila volumi più medaglie, stampe e quadri: fu lui l'ispiratore e il collaboratore di Perrault nella costituzione di questa galleria di medaglioni letterari ognuno dei quali è accompagnato, anche nell'edizione moderna, dalla "gravure» col corrispondente ritratto. Ma se la mano metodica del collezionista si riconosce nella genesi del volume, per la sua sintesi di parola e di immagine, non vi è dubbio che la celebrazione del «siècle de Louis le Grand» in un florilegio di vite d'uomini illustri rispecchia pienamente la posizione di Perrault nella stagione della sua maturità letteraria.

Una teoria di «moderni», tutti appartenenti almeno per un lembo della loro vita al XVII secolo, anche quelli nati in un'altra età; allineati senza alcuna preoccupazione cronologica; immobilizzati in una gerarchia ideale che privilegia gli uomini di chiesa, li fa seguire dagli uomini di guerra, quindi da scimziati, letterati e «artisans» (architetti, pittori, musicisti, orafi...), come ripetendo nell'ordine del libro una razionalità che 
Perrault attribuiva alla storia. All'interno dei ritratti dedicati ad ognuno, emerge ancora un gusto classico della simmetria, nella tendenza a comporre i giudizi nella forma del «parallèle» (si veda quello, felice, tra Descartes e Gassendi). La seconda parte del volume non ha la funzione di spostarne i limiti cronologici, ma di riequilibrare le masse, raddrizzare le imperfezioni nella composizione dell'insieme. Pochi condottieri erano rappresentati nella prima parte: ecco creata, nella seconda, l'adeguata compensazione.

Perché centodue? Lo strano numero lascia intravedere la falla nell'edificio armonioso, o piuttosto la vena anticonformista che serpeggia nell'opera di un autore pur ossequioso alle ortodossie del suo tempo. I due in più non sono due nomi qualunque: si chiamano Arnauld e Pascal. Un veto dall'alto ha tenuto i due giansenisti ostinatamente fuori da ogni edizione ufficiale del volume, in una sorta di limbo, sempre in attesa di essere riammessi nella galleria costituita a gloria di Luigi XIV. In realtà, gli esemplari del volume circolavano segretamente con le pagine proibite: l'editore non rinunciava all'attrattiva piccante dei ritratti censurati. Si avverte oggi uno strano gusto nel rileggere il breve testo dedicato a Pascal. Tra la Vie scritta da Mme Périer, l'odio e l'amore di Voltaire per il "génie prématuré», la fascinazione esercitata su Chateaubriand dall'«effrayant génie», anche Perrault ha dato il suo contribuito al mito del genio e dell'asceta che brucia le tappe, folgorante, impaziente, «surprenant» (p. 173). Ma c'è da dire che l'ammirazione di Perrault non va alle incompiute Pensées, agli abissi del pensiero e della poesia, ma allo stile, alla retorica, alla vivacità polemica, alla perfezione delle Provinciales. Un classico riconosœ un altro classico e vanta in lui il moderno che ha superato gli antichi in un genere che pure apparteneva loro: il dialogo.

Accuratamente annotata, corredata dall'indicazione delle varanti testuali e delle fonti da cui attingono le «vite», l'edizione che presentiamo riporta utilmente l'attenzione su quest'opera poco frequentata ma non minore, rivelatrice delle strategie di quel classicismo che riformula instancabilmente i rapporti tra il moderno e l'antico; rivestendo, qui, del paludamento di un genere antico l'elogio del presente: proiettando verso l'universale cio che ancora si sottrae alla profondità della storia. 